\title{
O SERTÃo EM ANÁLISE: DIÁLOGOS ENTRE EURICO ALVESE JOSÉ DE
} ALENCAR

\author{
Artur Vitor de Araújo Santana ${ }^{1}$; Valter Guimarães Soares ${ }^{2}$ \\ 1. Bolsista PROBIC/UEFS, Graduando em Licenciatura em História, Universidade Estadual de Feira de Santana, \\ email:artur.vitor.santana@hotmail.com \\ 2. Orientador, Departamento de Educação, Universidade Estadual de Feira de Santana, e-mail:vgsoares@gmail.com \\ 3. Participante do projeto Outras Bahias: imagens do sertão na história e na literatura, Departamento de Educação, \\ Universidade Estadual de Feira de Santana, e-mail:vgsoares@gmail.com
}

PALAVRAS-CHAVE: Alencar; Boaventura; intertextualidade.

\section{INTRODUÇÃO}

Na virada do século XIX, o sertão ganha relevância para se pensar o Brasil (SOARES, 2009). Arquivos de ideias e imagens da paisagem sertaneja e das suas gentes foram forjadas e cristalizadas no pensamento social brasileiro, muitas das quais remetem a estampas imaginárias construídas desde o período colonial. Tomando como pano fundo as representações de sertão e sertanejo na história e na literatura, nesse trabalho procurar escutar e analisar os ecos intertextuais do romance $O$ sertanejo (1875), de José de Alencar, no ensaio sócio-histórico Fidalgos e Vaqueiros (1989), do poeta e ensaista feirense Eurico Alves Boaventura.

Opero com a perspectiva do texto como um artefato social e cultural, por natureza habitado por diálogos (BARROS, 1997), intertextos (FREITAS, 2011) e apropriações (CHARTIER, 2002); e da leitura como uma prática plural, espaço de ressonância de diversas vozes, já que, na condição de sujeitos sociais e condicionados pelo tempo histórico em que vivemos, nos apropriamos de ideias e falas de outras pessoas. Nesse sentido, busco identificar e interpretar as formas de apropriaçãodo texto alencariano na construção discursiva do sertão e do sertanejo por parte de Eurico Alves, tencionando problematizar o modo como o ensaísta feirense se apropria ou intertextualiza o repertório do romancista.

\section{MATERIAL E MÉTODOS OU METODOLOGIA (ou equivalente)}

Preocupado em perceber a presença de Alencar no ensaio euriquiano (1989) tomo como operadores de análise os conceitos de intertextualidade, apropriação e leitura. Segundo Barros (1997), qualquer texto possui um "princípio dialógico", que seria um diálogo entre interlocutores ou discursos, que originaria a linguagem e atribui significações para as palavras e possibilita a sociabilização em comunidade. Brait (1997), em diálogo com Bakhtin, afirma que o dialogismo, é um conjunto de vozes que compõe o texto (polifonia), comumente desarmônicas entre si, mas que são articuladas pelo autor na construção do texto, sendo um exercício de leitura das práticas culturais, já que a concepção de texto não se restringe apenas ao que se está escrito (CHATIER, 2002).

Considerando a natureza híbrida do ensaio de Eurico Alves, situados na interface da ciência com a arte com predominância da primeira, já que o autor investe no sentido de conferir um estatuto científico ao trabalho que produziu, tomamos à noção de representação, defendida por Pesavento (2000), como elemento conceitual que permite articular o entrecruzamento entre o literário e o histórico, considerando que as representações expressam relações de força em uma dada estrutura social, remetendo para os diferentes modos como os sujeitos sociais percebem a si próprios, a sua época e 
ao mundo em que vivem, construindo a partir destas percepções sistemas de identidade, de crenças e de conhecimento (SOARES, 2009).

De forma abreviada, o percurso metodológico utilizado no processo de realização do trabalho constituiu-se basicamente em: a) levantamento e leitura da bibliografia: 1) teórica, com vistas a melhor explicitação do referencial teórico da pesquisa; 2) sobre a trajetória dos autores: memórias, biografias, posicionamento político, etc; 3) sobre as obras de Alencar e Boaventura (fortuna crítica); b) revisar a literatura que tematiza o sertão, c) análise textual meticulosa da obra tomada como objeto de pesquisa, de forma a "escutar" nela os ecos intertextuais dos escritos de Alencar.

\section{RESULTADOS E/OU DISCUSSÃO (ou Análise e discussão dos resultados)}

Neste trabalho, nos propomos analisar como Eurico Alves Boaventura, em sua obra Fidalgos e Vaqueiros (1989), se apropria/ler (d)o arquivo alencariano, quais os deslocamentos, permanências e similaridades entre a obra do ensaísta feirense e os romances de Alencar. Para isso, observamos em quais temáticas Boaventura intertextualiza os escritos do romancista, analisando os momentos que são citados, assim como as discussões em que foi silenciado. O escritor feirense utiliza como fontes e material para composição do ensaio vários romances, entre eles $O$ Guarani, A alma de Lázaro, Minas de Prata, O sertanejo, Sonhos de Ouro, Ubirajara, Iracema, Til, Guerra dos Mascates e O Guaratuja.

Deste conjunto de obras, coloco em destaque a análise da presença do romance O sertanejo (1977), devido à proximidade temática entre as duas literaturas, que se propõem discutir imagens de sertão e sertanejo. De forma surpreendente, este romance de Alencar, cuja obra é a que mais aparece no escrito de Boaventura, é citado diretamente apenas três vezes no volumoso ensaio. Desse estranhamento surge o problema que mudou os rumos da pesquisa, pois sendo Fidalgos e Vaqueiros uma mitologia/narrativa sertaneja, e considerando abundância dos escritos de Alencar, por que a pouca presença de $O$ sertanejo, obra que mais se aproxima tematicamente do intento euriquiano?

Afirmamos que os escritos alencarianos e o ensaio euriquiano são utilizados como fontes históricas, tendo como preocupação construir uma identidade nacional, inserindo o vaqueiro nesse processo, compartilhando um mesmo projeto de Brasil: uma nação viril. Sendo esse o elo principal entre os literatos, que se debruçam na problemática de pensar outras narrativas para o país, de acordo com as demandas contemporâneas ao período que foram escritos os livros que utilizamos como objeto de análise.

A obra Fidalgos e Vaqueiros se estende por onze capítulos, possuindo 422 páginas. Em linhas gerais, Alencar aparece citado no decorrer de cinco capítulos ${ }^{1}$, em momentos muito bem delimitados, já que o ensaísta feirense recorre ao romancista quando pretende ilustrar o luxo da aristocracia do pastoreio ou criticar algum comentário do escritor que conteste a pomposidade sertaneja.

As citações de $O$ sertanejo estão concentradas nos capítulo seis (Fidalgos que sabem aboiar) e sete (A paisagem decora a casa da fazenda), que são os maiores

\footnotetext{
${ }^{1}$ CAP. 5: Perfil da casa - da -fazenda (p. 95 - 170): O Guarani; A alma de Lázaro; Minas de Prata; Sonhos de Ouro; O sertanejo. CAP. 6: Fidalgos que sabem aboiar (p. 171 - 250): O Guarani; Ubirajara; Iracema; O sertanejo. CAP. 7: A paisagem decora a casa da fazenda (p. 251 - 300): O sertanejo; Til; Guerra dos Mascates: CAP. 8: Sob a luz dos grandes candeeiros belgas (p. 301 - 332): Til; Guerra dos Mascates; O Guaratuja; CAP. 9: Prestígio social da casa-da-fazenda (p. 333 - 388): O Guarani.
} 
capítulos do livro ${ }^{2}$. No sexto capítulo o autor apresenta a tese central do ensaio, que define a formação do homem sertanejo, assim como suas características, a exemplo da virilidade, coragem e força, apresentando um fidalgo que também exerce o ofício de vaqueiro, estabelecendo uma crítica ao trabalho freyriano e ao senhor da casa-grande (SOARES, 2009) que é retratado como um senhor que exercia apenas a voz de mando, diferente do aristocrata do sertão, que para Boaventura teria o prazer de "sujar as mãos" na labuta vaqueira.

No sétimo capítulo, ainda discutindo sobre a construção do homem sertanejo, Boaventura observa a relação dos fidalgos como seus cavalos, que se tornam representações de seu poder e da sua virilidade. Assim como apresenta uma cultura sertaneja, atribuindo um maior enfoque principalmente ao conhecimento popular das ervas e plantas, apresentando uma farmacologia sertaneja, além de uma transição do uso comunitário das terras para o estabelecimento das cercas e de um novo formato das fazendas de criar.

A primeira referência direta do romance $O$ sertanejo (1977) no ensaio euriquiano, está inserido em uma discussão que toma o período romântico como um movimento político que se volta para o interior do Brasil, citando concomitantemente com outros três romances, Iracema, Ubirajara, e $O$ Guarani. Ao citar o livro $O$ sertanejo juntamente com as obras indigenistas, Boaventura afirma que Arnaldo, personagem principal do romance, seria mestiço de indígena, o que contradiz a tese de Alencar, que toma o personagem como "sertanejo" que em substituição do índio, tornase o cerne da nacionalidade.

Diante da afirmação de Eurico Alves, surgiu à seguinte questão: Por qual motivo Arnaldo é descrito como mestiço de indígena na obra euriquiana? Talvez a resposta mais viável, seja a forma como Alencar descreve o sertanejo, selvagem e apegado a terra, que se distancia da imagem dos sujeitos do sertão que Boaventura propõe defender, pois sua tese principal se preocupa em apresentar a fazenda de criar como um espaço da fidalguia, de uma nobreza e civilidade que se equipara ou até supera os fidalgos do litoral. Defender as adjetivações que José de Alencar personifica em Arnaldo, iria de encontro a uma imagem que o ensaísta feirense está disposto a contrapor.

\section{CONSIDERAÇÕES FINAIS (ou Conclusão)}

Após este olhar panorâmico sobre a presença dos textos de Alencar na composição de Fidalgos e Vaqueiros, é possível arriscar algumas afirmações. A primeira delas é que as obras se aproximam em diversos aspectos, o que pode explicar a marcante presença intertextual do arquivo alencariano no ensaio do poeta feirense. Assim, é possível perceber que Eurico Alves se utiliza do romanceiro do escritor cearense para fundamentar a sua tese por ele empenhada: a da existência da civilização do pastoreio, reafirmando a ideia do sertão como lugar da nacionalidade autêntica. Civilização, vale enfatizar, em tudo superior a outras formações sociais, em especial àquela que se constituiu na beira do mar, nos engenhos adocicados pela cana de açúcar.

Porém, o intertexto nem sempre é pacífico, já que marcado pela seletividade. Quando conveniente, o ensaísta feirense sombreia e silencia qualquer citação do romancista que remeta a um sertão seco, negro/mestiço, pobre, inculto, aspectos muito latentes na obra, mas contrariam a imagem de sertão e sertanejo que Boaventura projeta na construção de seu ensaio.

\footnotetext{
${ }^{2} \mathrm{O}$ capítulo 6 possui 79 páginas (pp. 171-250) e o capítulo 7 tem 49 páginas (pp. 251-300), perdendo na quantidade de laudas apenas para o quinto capítulo, que possui 75 páginas (pp. 95-170).
} 
Por fim, ainda é possível afirmar que a despeito da proximidade temática entre o romance $O$ sertanejo e o ensaio, a pouca referência direta do romance é estratégica, uma tentativa de conferir a sua produção um verniz científico. Nesse sentido, Eurico opera uma travessia da escrita poética para uma narrativa histórico-sociológica, portanto com pretensão científica, supostamente mais próxima da verdade. No ensaio há diferenças acentuadas entre as apropriações de textos de matiz acadêmica e aqueles outros que se afastam deste formato, como soa acontecer com as produções dos viajantes naturalistas e textos os textos literários de diversos gêneros. Assim compreendido, entende-se distanciamentos de Boaventura do arquivo alencariano, ou sua utilização, na medida em que interessa e se aproxima da imaginação histórica que configura a civilização do pastoreio, aqui apenas e tão somente como fonte de informações, como referendo, ou com um caráter ilustrativo. O discurso é marcadamente positivo, busca objetividade na forma de representar, estabelecendo a dicotomia entre verdade $\mathrm{x}$ invenção, afirmando a ciência como "lugar da verdade na apreensão do real, e a literatura como sistema da arte, território do fictício, da subjetividade e do imaginário", como nos apresenta Soares ${ }^{3}$.

\section{REFERÊNCIAS}

ALENCAR, José de. O sertanejo. 5. ed. São Paulo: Melhoramentos, 1977.

BARROS, Diana Luz Pessoa de. Contribuições de Bakhtin às teorias do discurso. IN: BOAVENTURA, Eurico Alves. Fidalgos e Vaqueiros. Salvador: UFBA, Centro Editorial e Didático, 1989.BRAIT, Beth (org.). Bakhtin, dialogismo e a construção do sentido. Campinas, SP: UNICAMP, 1997.

BRAIT, Beth. Bakhtin e a natureza constitutivamente dialógica da linguagem. IN: BRAIT, Beth (org.). Bakhtin, dialogismo e a construção do sentido. Campinas, SP: UNICAMP, 1997

CHARTIER, Roger. Representações e práticas: Leituras camponesas no século XVIII. In: Leituras e leitoras na França do Antigo Regime. São Paulo: UNESP, 2004

Textos, impressos, leituras. História cultural: entre práticas e representações. Lisboa: Difel, 1992.

FREITAS, Antonio Carlos Rodrigues de. O desenvolvimento do conceito de intertextualidade. In: Revista Icarahy. Rio de Janeiro, nº 6, pp. 27-42, 2011.

SOARES, Valter Guimarães. Cartografia da saudade: Eurico Alves e a invenção da Bahia sertaneja. Salvador: EDUFBA; Feira de Santana : UEFS Editora, 2009, p. 59.

Conversa de Arquivo: Eurico Alves, leitor de Euclides. Légua \& meia: Revista de literatura ediversidade cultural. Feira de Santana, UEFS, v. 7, nº 5, 2009b, p.56-75.

\footnotetext{
${ }^{3}$ SOARES, Valter Guimarães. Cartografia da saudade...p. 37.
} 